\title{
Characterization of Horse Use in Therapeutic Horseback Riding Programs in the United States: A Pilot Survey
}

\author{
Emily Watston \\ Murray State University \\ Amanda Davis \\ Murray State University \\ Rebecca K. Splan \\ Delaware Valley University \\ C.A. Shea Porr \\ Murray State University
}

Follow this and additional works at: https://digitalcommons.murraystate.edu/faculty

Part of the Animal Sciences Commons

\section{Recommended Citation}

Watston, Emily; Davis, Amanda; Splan, Rebecca K.; and Porr, C.A. Shea, "Characterization of Horse Use in Therapeutic Horseback Riding Programs in the United States: A Pilot Survey" (2020). Faculty \& Staff Research and Creative Activity. 71.

https://digitalcommons.murraystate.edu/faculty/71

This Peer Reviewed/Refereed Publication is brought to you for free and open access by Murray State's Digital Commons. It has been accepted for inclusion in Faculty \& Staff Research and Creative Activity by an authorized administrator of Murray State's Digital Commons. For more information, please contact msu.digitalcommons@murraystate.edu. 
Title: Characterization of Horse Use in Therapeutic Horseback Riding Programs in the United States: A Pilot Survey

Author Names and Affiliations:

Emily Watson ${ }^{a}$, Amanda Davis $^{a}$, Rebecca Splan ${ }^{b}$, C.A. Shea Porr ${ }^{a}$

${ }^{a}$ Murray State University, 2111 College Farm Road, Murray, KY, USA, bDelaware Valley University, 700 E. Butler Ave., Doylestown, PA, USA

eamwatson01@live.com, adavis53@murraystate.edu, rebecca.splan@delval.edu, cporr@murraystate.edu

(1)

Corresponding author: Emily Watson

Present Address: 159 Mountain Creek Ct., Jonesborough, TN, USA; E-mail eamwatson01@live.com

\section{Abstract}

With increasing public scrutiny on animal welfare, it behooves those involved in the equine industry to revisit best management practices to ensure these support healthy horses. There is little published research on how horses are used in the equine industry, particularly in therapeutic horseback riding (THR) programs. While there is a large amount of information on the benefits of THR programs to the participants, there is little published information available about the horses. Therefore, the objective of this survey was to gather data regarding horse use and care in Professional Association of Therapeutic Horsemanship International (PATH Intl.)-affiliated THR programs in the United States to help establish a foundation for a standard of care. A 20-question survey sent to 659 PATH Intl.-affiliated THR programs returned a $40 \%$ response rate. Demographics demonstrated that the median number of horses in each program was 10; geldings outnumbered mares; most horses were between 16 to 20 years of age; and Quarter Horse or stock-type breeds predominated. Sessions lasted an average of 8 weeks with 45 minute lessons. Horses were typically ridden by clients 4 days/week and 2 hours/day. Most horses were donated to the programs, participated for approximately 7 years, and left due to aging. Limb lameness and back soreness were the top health issues noted, with only a small percentage of colic and ulcers reported. More horses received NSAIDs for a lameness issue, chiropractic adjustment, and massage than any other supplemental care or complementary therapy. Based on data gathered in this survey, THR horses were not worked excessively. Horses were ridden less than PATH Intl.'s maximum recommendation of 6 hours/day and 6 days/week and less than those used in university programs. Horses in THR programs also appeared to have fewer reported health issues as compared with data in other national reports.

Keywords: horse use, therapeutic horseback riding 
Introduction

Animal-assisted intervention, including therapeutic horse riding (THR), is designed to promote improvement in a person's physical, social, emotional and/or cognitive functioning, and is directed or delivered by a practitioner with specialized expertise [1]. While there is abundant research on the benefits of THR to human participants $[1,2,3,4,5,6]$, there is little information regarding effects on horses involved in such programs [7].

The Professional Association of Therapeutic Horsemanship International (PATH Intl.) seeks to both credential and improve therapeutic institutions in the United States and protect therapy horses [8]. PATH Intl. regularly publishes a Standards for Certification and Accreditation Manual that includes guidelines for implementing a training/conditioning program; observing physical soundness and behavior of horses before the therapy session; maintaining thorough health records; limiting horse workloads to no more than 3 continuous hours and no more than 6 total hours/day; and recommending a maximum work week of 6 days based on the expectation that interacting with participants can be stressful $[9,10]$. In order to be accredited or certified by PATH Intl., facilities must follow the published guidelines.

Knowing how horses are managed and what health issues are more prevalent in other equine activities can help those working with THR horses to better care for their animals. Therefore, the objective of this study was to gather data regarding horse use and care in PATH Intl.-affiliated THR programs in the United States as a preliminary step toward defining a common standard of care.

\section{Materials and Methods}

Neither IRB nor IACUC approval was required since horse owners/managers were surveyed anonymously and horse use was not altered for the purpose of the survey.

\subsection{Survey Instrument}

Survey questions were adapted from a previously validated survey on horse use in university programs [11]. Modifications to improve the university survey's fit to THR programs included adding Questions 1, 3, 4, 10, and 13 (Table 1); combining student contact hours questions to form Question 2; changing rider experience categories from years of experience to rider ability in Question 9; and removing questions about student majors, horses being used by other university programs like a veterinary school, characterizing horse behavior, and land area [11]. The final 20 questions were divided into three sections: General Program Questions $(n=10)$, Equine Health and Care $(n=6)$, and Equine Demographics $(n=4 ;$ Table 1). The survey instrument for this study was reviewed by four faculty members in university Equine Science programs and was subjected to a post-hoc evaluation for content by a professional in the THR industry, but was not validated. However, the university horse use survey by Zhao [11] had been released for a pilot test, and modifications were made before the full survey release.

Table 1. Survey questions used to gather information on therapeutic horseback riding program structure, horse use, and horse health issues

\section{General Program Questions}


1 Do you offer riding in sessions? If yes, how long do your sessions last? If no, Yes/No* please explain how your program works.

2 On average, how many days per week and hours per day are horses ridden by clients? Please enter a number.

3 How often are horses schooled by someone more experienced than a client? Please be as specific as possible.

4 During each lesson, approximately how long do horses stay in each gait?

- Walk

Numeric, Open-ended other

Open-ended

- Trot/Jog

- Canter/Lope

- Other comments

5 How do you track horse use in your program? Check all that apply.

- Daily

- Weekly

- Verbally

- Written

- Other. Please explain

6 How are horses in your program acquired? Enter a percentage acquired by each method.

- Donated

- Purchased

- Privately owned and leased to program

- Other. Please explain

7 On average, how many years do horses remain in your program?

8 What is the most common reason horses leave your program?

- Chronic lameness

- Personality or behavior changes

- Aging

- Other. Please explain

9 What percentage of clients fall into the following categories relative to their riding ability?

- Very Limited

- Limited

- Moderate

- Moderately Advanced

- Advanced

10 What percentage of clients with the following does your program serve? Enter a percentage of your total client base in each applicable category.

- Autism Spectrum Disorder

- Cerebral Palsy

Numeric, Open-ended other 
- Down Syndrome

- At-risk youth (behavioral disturbances)

- Veterans rehabilitation

- Other. Please explain

\section{Equine Health and Care}

11 What percentage of horses in your program are shod?

Numeric

- Barefoot

- Front shoes only

- Front and rear shoes

12 What are the types and frequencies of physical health issues typically encountered each year? Please enter a total number of horses with these issues.

- Limb lameness (knee/hock, fetlock, or pastern issue)

- Back soreness

- Shoulder or hip lameness

- Ulcers

- Colic

- Hoof abscesses

- Hoof wall cracks

- Other. Please explain

13 How do you determine if horses need time off from the program? Check all that apply.

Multiple selection, Open-ended other

- Frequent biting of horse handler while ridden by client or being tacked

- Excessive unwillingness to perform tasks when asked

- Personality changes with no obvious cause (for example, an injury to the horse may result in personality changes, so that would be an obvious cause)

- Other. Please explain

14 In the last year, what percentage of horses have received the following:

- Glucosamine

Numeric,

- Joint injections Open-ended other

- Chiropractic adjustment

- Massage

- NSAIDS (bute, banamine) for lameness

- NSAIDS (bute, banamine) for reasons other than lameness

- Other. Please explain

15 How often are health evaluations of horses conducted by staff and/or veterinarians? Check all that apply.

Multiple selection, Open-ended other

- Daily by staff 
- Weekly by staff

- Monthly by veterinarian

- Once per session by veterinarian

- Other. Please explain

16 How are horses primarily housed when not in use? Please enter a

Numeric, percentage.

- Stall

- Dry lot (dirt paddock with no grass)

- Small paddock (with some grazing)

- Pasture (with significant grazing)

- Other. Please explain

\section{Equine Demographics}

17 How many horses are in your therapeutic riding program?

Numeric

18 How many of your horses are each gender?

Numeric

- Mare

- Gelding

- Stallion

19 How many of your horses belong to each breed?

Numeric,

- Quarter Horse, Paint, or other stock type

- Pony breeds

- Draft or Draft-cross

- Thoroughbred

- Warmblood

- Other. Please explain

20 How many of your horses fall into the following age ranges?

Numeric

- Less than 5 years of age

- 6 to 10 years of age

- 11 to 15 years of age

- 16 to 20 years of age

- Greater than 20 years of age

*Due to ambiguity, Question 1 yielded both session and lesson length data.

72 The survey was sent to 659 PATH Intl.-affiliated THR programs in the United States. Programs were

73 selected from PATH Intl.'s website using the 'Find a Center' function Jun.-Aug. 2017 and filtered by

74 activity (Therapeutic Riding). An initial invitation email containing a link to the survey (formed in

75 SurveyMonkey ${ }^{\circledR}$ ) was sent to each recipient via Google Mail Merge. The SurveyMonkey ${ }^{\circledR}$ collection web

76 link was open from Sep. 20 to Nov. 15, 2017. Reminder emails were sent using a modified Dillman

77 method at two, four, and six weeks [12].

$78 \quad 2.3$ Data Analysis 
At the conclusion of the survey, an Excel data file was downloaded from SurveyMonkey ${ }^{\circledR}$. All survey responses were reviewed and cleaned to a consistent format for data analysis; e.g., questions asking the respondent to enter a number or percentage were converted to Arabic numerals (six to $6,60 \%$ to 60 ). If a respondent entered a range of numbers or percentages, ranges were averaged to better facilitate data analysis (e.g. 6-12 to 9, 4-6 to 5). Question 3 was coded, grouping similar responses for statistical evaluation. In addition, some responses within a specific question were removed because the respondent was not specific or misunderstood the question.

Due to the non-normality of the data, median and Interquartile Range (IQR) were reported, and outliers were identified using boxplots created in Excel 2016 and excluded from further data analysis.

Spearman's Rank correlations between measures of horse workload in THR programs and percentage of horses with reported injury were determined. Significance was declared the 0.05 alpha level, and pvalues were adjusted for multiple comparisons using a step-down Šidák adjustment. Numeric data were treated as ordinal while non-numeric data were treated as categorical for the purposes of analyses.

\section{Results}

A total of 270 responses were received for a response rate of $40.7 \%$. After reviewing data, six responses were considered ineligible for data analysis because the respondent indicated the program did not ride and, therefore, did not participate in THR. Across the survey, a maximum of 264 responses were eligible for analysis (40.1\%). The number of responses collected decreased as the survey continued, ending at 246 total responses to Question 20. From total responses to each question, 2-24\% were removed due to not participating in THR, misunderstanding the question, lacking specificity, and being outliers.

All questions except for Question 10 had responses that required cleaning. Responses in which 'min' or '\%' was dropped to provide a numeric answer for analysis in Excel were not included in cleaned percentages. More than half of responses to Questions 1 (session length 68\%, lesson length $59 \%$ ), 3 (100\%), 4 (56\%), and 7 (50\%) were cleaned. Question 1 was inherently ambiguous as session was not defined in the question, and respondents entered session and/or lesson length. The data was reviewed and split to session and lesson length for analysis. All responses to Questions 3 were cleaned as this was an open-ended question; responses were reviewed and grouped into response codes for easier analysis. Questions 4 and 7 responses were often a phrase or range of time (e.g. "half of the time", "15 to 20 minutes", "until the horses die", " 5 to 10 years"), which were cleaned to a numeric answer. For the remaining questions, $0-38 \%$ of responses were cleaned.

\subsection{Equine Demographics}

The median number of horses in THR programs was 10 horses (IQR=7-14; $n=232$ ). Median percentages of mares and geldings were 33.3\% (IQR=20-50; $n=235)$ and 66.7\% (IQR=50-80; $n=237)$, respectively. The majority of horses belonged to three breed categories: Quarter Horse, Paint, and other stock-type (53.1\%, IQR=35.1-72.7; $n=240)$; pony (17.8\%, IQR=8.3-28.6; $n=238)$; or draft and draft-cross (10\%, IQR=0-21.4; $\mathrm{n}=237)$. The most common age of horses in THR programs was 16 to 20 years $(33.3 \%$, IQR=20-49.7; $n=238$ ) followed by more than 20 years $(25 \%, I Q R=12.5-40 ; n=235)$ and 11 to 15 years (22.2\%, IQR=11.8-38.5; $\mathrm{n}=238)$.

\subsection{General Program Responses}


THR programs were highly variable in riding program format, with riding time scheduled in sessions and/or individual lessons. In this survey, a THR 'session' is defined as a set group of rides over a period of time, while a THR 'lesson' is defined as a single ride, either within or independent of a particular session. For example, a THR program may have an 8-week session with one 45 minute lesson/week. Median session length was 8 weeks (IQR=6-10; $n=109$ ) while median lesson length was 45 minutes (IQR=37.5-60; $\mathrm{n}=142$ ). One program indicated some clients could have ongoing weekly lessons without regard to sessions, while others rode weekly for 8 week sessions. Eighteen programs indicated they provided lessons year-round with no defined session.

Horses used for THR were ridden by clients 4 days/week (IQR=3-5) and 2 hours/day (IQR=2-3; n=241). Median total hours/week, calculated by multiplying days/week and hours/day within the same response, was 9 hours/week (IQR=6-12; $n=233$ ). Of all programs, $65.2 \%$ indicated horses were ridden and schooled 1-4 times/week by someone more experienced than a client $(n=259)$. Horses spent $80 \%$ of client ride time at the walk (IQR=69.5-89.0; $n=212$ ). The majority of respondents $(81.0 \%)$ indicated that horse use was tracked on a daily basis; over half of respondents (58.9\%) indicated use was tracked through hardcopy records while 12 respondents (4.6\%) indicated horse use was tracked only verbally $134(n=264)$.

Regarding horse acquisition, $50 \%$ of horses were donated (IQR=20-89.4), 5\% were purchased (IQR=0$25)$, and $20 \%$ were privately owned and leased to THR programs (IQR=0-50; $n=230)$. The median length of time a horse spent in a program was 7 years ( $I Q R=5-10 ; n=216)$, ranging from 2 to 15 years. Horses most commonly left THR programs due to aging $(56.1 \% ; n=253)$.

Programs were asked to rate the riding ability of their clients, regardless of disorder or disability, in five categories: very limited, limited, moderate, moderately advanced, and advanced (Table 2). The majority of riders were rated very limited, limited, and moderate in their riding ability while $40 \%$ (IQR $=30-60$;

$142 \mathrm{n}=221$ ) of clients had Autism Spectrum Disorder, 10\% (IQR=5-15; n=216) had Cerebral Palsy, 8\% (IQR=0$14315.5 ; n=216)$ were at-risk youth with behavioral disturbances, and 5\% (IQR=2-10; $n=209)$ had Down 144 Syndrome.

Table 2. Riding ability category definitions, median percentage of clients in each category, IQR, and $n$

\begin{tabular}{|c|c|c|c|c|}
\hline $\begin{array}{l}\text { Riding Ability } \\
\text { Category }\end{array}$ & Description & $\begin{array}{l}\text { Median } \\
\text { Percentage } \\
\text { of Clients }\end{array}$ & IQR & $\mathrm{n}$ \\
\hline Very Limited & $\begin{array}{l}\text { Unable to steer horse; frequent inappropriate pulling } \\
\text { on horse's mouth/face; very little trunk and upper body } \\
\text { support; travels primarily at the walk; requires one or } \\
\text { more sidewalkers (someone walking beside the horse } \\
\text { to support the rider) }\end{array}$ & 20 & $10-44$ & 225 \\
\hline Limited & $\begin{array}{l}\text { Able to steer horse, but may occasionally } \\
\text { inappropriately pull on horse's mouth/face; some trunk } \\
\text { and upper body support; can cue horse with legs; } \\
\text { travels primarily at the walk and trot; may require one } \\
\text { sidewalker }\end{array}$ & 25 & $15-40$ & 223 \\
\hline
\end{tabular}


Moderate Able to steer horse with little inappropriate pulling on horse's mouth/face; good trunk and upper body support; can cue horse with legs; travels primarily at the walk and trot; may require one sidewalker

Moderately Able to steer horse with no inappropriate pulling on Advanced horse's mouth/face; good trunk and upper body support; can cue horse with legs; travels primarily at the walk and trot; does not require a sidewalker

Advanced

Able to independently steer horse and cue with legs; excellent trunk and upper body support; can travel at the lope; does not require a sidewalker

\subsection{Equine Health and Care}

Programs provided the number of horses that had experienced a certain health issue in the previous year. Responses were converted to the percentage of total horse population within each program by dividing by the total number of horses provided in Question 17 of the demographics section. The top health issues reported in THR horses were limb lameness (20\%, IQR=6.9-30; $n=211$ ) and back soreness (11.8\%, IQR=0-25.3; $n=208)$. Surprisingly, colic (0\%, IQR=0-10, max. 27.3; $n=212)$ and ulcers ( $0 \%, I Q R=0$ 0 , max. 7.7; $n=174)$ were minimally reported. The majority $(75 \%, I Q R=44.5-99.6 ; n=227)$ of horses were barefoot and wore no shoes, $18 \%$ wore front shoes only (IQR=0-38.8; $n=227$ ), and very few wore front and rear shoes $(0 \%, I Q R=0-7$, max. $25 ; n=201)$.

The most common reason - other than a physical issue - horses were given time off from the program was personality changes with no obvious cause (86.7\%; $n=240)$. Horses received NSAIDs for a lameness issue $(10 \%, I Q R=0-20 ; n=224)$, chiropractic adjustment $(5 \%, I Q R=0-50 ; n=234)$, and massage $(2 \%$, IQR=0$50 ; n=234$ ) than any other supplemental care or complementary therapy. Glucosamine was minimally reported ( $0 \%, I Q R=0-18.75$, max. $75 ; n=210)$. Staff performed horse health evaluations daily in $84.2 \%$ and weekly in $12.9 \%$ of responses, while a veterinarian performed health evaluations monthly in $9.2 \%$ and once/session in $37.1 \%$ of programs $(n=240)$. Horses were most often housed on pasture when not in use $(50 \%$, IQR=0-95; $n=190)$.

\subsection{Correlations between horse workload and reported injury}

Correlations between various measures of horse workload in THR programs and the percentage of horses with reported injury are shown in Table 3. Three correlations trended toward statistical significance before adjustment for multiple comparisons, but were not significant after adjustment.

Table 3. Spearman's Rank correlations between horse workload and reported injury in therapeutic horseback riding programs

\begin{tabular}{lcccc}
\hline Relationship & $n$ & $r$ & p-value & Adj p-value* \\
\hline 1. Session length (wk) to \% of horses w/ limb lameness & 88 & 0.099 & 0.358 & 0.830
\end{tabular}




\begin{tabular}{|c|c|c|c|c|}
\hline 2. Session length (wk) to $\%$ of horses $w /$ back soreness & 88 & 0.038 & 0.724 & 0.924 \\
\hline 3. Lesson length $(\mathrm{min})$ to $\%$ of horses $\mathrm{w} /$ limb lameness & 109 & -0.080 & 0.409 & 0.830 \\
\hline 4. Lesson length $(\mathrm{min})$ to $\%$ of horses $\mathrm{w} /$ back soreness & 106 & 0.115 & 0.240 & 0.808 \\
\hline 5. Total ride $\mathrm{hr} / \mathrm{wk}$ to $\%$ of horses $\mathrm{w} /$ limb lameness & 190 & 0.106 & 0.147 & 0.719 \\
\hline 6. Total ride $\mathrm{hr} / \mathrm{wk}$ to $\%$ of horses $\mathrm{w} /$ back soreness & 184 & 0.185 & 0.011 & 0.129 \\
\hline 7. Ride $\mathrm{hr} / \mathrm{d}$ to $\%$ of horses $\mathrm{w} /$ limb lameness & 196 & -0.023 & 0.746 & 0.924 \\
\hline 8. Ride $\mathrm{hr} / \mathrm{d}$ to $\%$ of horses $\mathrm{w} /$ back soreness & 196 & 0.096 & 0.184 & 0.759 \\
\hline 9. Ride $d / w k$ to $\%$ of horses $w /$ limb lameness & 209 & 0.159 & 0.022 & 0.214 \\
\hline 10. Ride $d / w k$ to $\%$ of horses $w /$ back soreness & 206 & 0.108 & 0.123 & 0.693 \\
\hline 11. Length in program ( $\mathrm{yr}$ ) to $\%$ of horses $\mathrm{w} /$ limb lameness & 171 & -0.084 & 0.247 & 0.808 \\
\hline 12. Length in program ( $y r)$ to $\%$ of horses $w /$ back soreness & 168 & -0.169 & 0.029 & 0.254 \\
\hline
\end{tabular}

* Šidák adjusted for multiple comparisons

Discussion

The information reported here is the first known report of equine demographics and horse workloads in THR programs. These responses provide basic information characterizing the surveyed programs; however, only limited conclusions can be drawn as reasons for some responses were not collected.

\subsection{Equine Demographics}

Equine operations have been defined by the United States Animal and Plant Health Inspection Service (APHIS) as small (5-9 equids), medium (10-19 equids), or large (20+ equids) [13]. Based on those definitions, THR programs were typically medium sized with a median of 10 equids/program. Equine demographics within the variety of disciplines in the equine industry are difficult to acquire. State-level surveys have reported equine numbers, breeds, and use, but do not often report age or gender $[14,15]$. This survey showed the number of mares (33.3\%) and geldings $(66.7 \%)$ used in THR programs were different as compared to the number of each gender reported nationally $(48.6 \%$ and $39.9 \%$, respectively) [13]. Also, there were more geldings reported in university programs [11]. This may be due to the perception of equine gender behavior; geldings are perceived to be more calm, reliable, and easygoing than stallions or mares [16]. Stock-type horses are common and popular in the United States and accounted for $53.2 \pm 2.6 \%$ of horses in the United States [13]. In this survey, American Quarter Horses, Paints, and other stock-type horses were grouped and accounted for $53.1 \%$ of equids used in THR programs.

Relative to age, APHIS used birth to 6 months (4.3\%), 6 months to 5 years (18.6\%), 5 to 20 years (65.6\%), and $20+$ years (11.4\%) to categorize horse age groups [17]. For THR programs, the majority of horses (33.3\%) were aged 16 to 20 years. When data for THR horses from 5 to 20 years are combined, the 
number is similar to that reported previously (62.2\% and $65.6 \%$, respectively) [17]. The majority of horses (75.6\%) used in university programs were also 5 to 20 years [11]. APHIS reported the number of older horses increased by $3.8 \%$ between 2005 and 2015 [17]. This increase in the number of older horses nation-wide may be related to why the second greatest age group of THR horses was $20+$ years (25.0\%).

\subsection{General Program Responses}

Equine workload has been defined previously based on time ridden and type of activity [18]. In THR programs, horses were typically ridden by clients 9 hours/week which would equate to a heavy workload based on time (4-5 hours/week) [18]. However, THR horses primarily exercised at a walk $(80 \%$ of time spent), which would equate to a light workload (recreational riding, beginning training, occasional showing) [18]. Many respondents also indicated that horses were ridden 1-4 times each week by more experienced riders. The amount of time or type of activity this required of the horse was not explained, but does imply the workload of THR horses was higher than that reported in Question 2. This illuminates the difficulty in defining "workload" across equestrian disciplines when attempting to define a common standard of care.

Tracking animal use is important when considering equine welfare. In university programs, animal use was reported on a daily basis using either written (73.8\%) or verbal (57.8\%) communication [11]. This is compared to THR programs, which used written only (58.9\%) or verbal only $(4.6 \%)$ methods on a daily basis, while $13.7 \%$ used both. In both situations, written communication was more often used to track horse use.

The most common way THR programs acquired horses was through donation. This is compared to horses in university programs, where $57.9 \%(n=11 / 19)$ of programs acquired $90 \%$ or more of their horses through donations, and $78.5 \%$ ( $n=15 / 19$ ) of programs acquired $50 \%$ or more of their horses through donations [11]. Horses remained in THR programs for 7 years whereas university programs generally kept horses less than $10 \mathrm{yr}$, with $44.4 \%$ of horses remaining in a program for less than 5 years and $44.4 \%$ remaining for 6 to 10 years [11]. Although the question was not asked in either survey, lack of funding to purchase new animals in one university program has been reported [19]. Donations were the primary means of animal acquisition in both THR and university programs, so the same funding issue may be present in THR programs.

While there have been many reports on the benefits of THR on human riders, this is the first known data collected on the percentages of client riding ability and disability group. Based on question limitations, no conclusions or comparisons related to horse use or health can be drawn at this time.

\subsection{Equine Health and Care}

A variety of management issues should be considered when caring for horses. Relative to hoof care, horses can be maintained barefoot or wear shoes on both front hooves, both rear hooves, or on all four. In university programs, only $34.2 \%$ of horses were barefoot [11] as compared to $75 \%$ in THR programs. Also, while few THR horses wore both front and rear shoes, $43.6 \%$ of university horses did the same. One THR respondent noted that horses were not allowed to wear rear shoes; this is not specified in PATH Intl.'s standards manual [10], so it is assumed this was a program rule. Horses were housed in 
stalls more often than on pasture in university programs [11], whereas THR programs housed horses on pasture more often than in stalls.

In this survey, the identity of the respondent for a given THR program is unknown. Therefore, reported health related issues may not have been verified by a licensed veterinarian. In university programs, horses were most often checked by faculty or staff on a daily basis $(52.6 \%)$ and by veterinarians as needed (66.7\%) [11]. The majority of respondents in the THR survey indicated horse health evaluations were performed by staff daily $(84.2 \%)$ and only $9.4 \%$ indicated a veterinarian performed evaluations monthly. Many respondents reported routine veterinarian visits coincided with spring and fall vaccinations. With this in mind, THR horses experienced a lower incidence of limb lameness (20\% vs. $29.7 \%$ ), colic ( $0 \%$ vs. $16.5 \%$ ), and hoof abscesses ( $0 \%$ vs. $17.0 \%$ ), but a higher incidence of back soreness $(11.8 \%$ vs. $4.8 \%)$ in the previous year as compared to other national reports $[20,21]$.

Many nutritional supplements and complementary therapies are available for horses. Nationally, the most common supplements and treatments used in horses included corticosteroid and other joint injections $(21.2 \pm 5.2 \%)$, nutritional or joint supplements $(29.2 \pm 3.7 \%)$, chiropractic adjustments $(17.2 \pm$ $3.2 \%)$, and massage $(10.4 \pm 2.2 \%)$ [20]. In university programs, glucosamine was used in $7.0 \%$ of horses, and common therapies included joint injections (18.3\%), chiropractic adjustments (5.0\%), and massage (2.8\%) [11]. The most common supplement or treatment received by THR horses was NSAIDs for a lameness issue (10\%) followed by chiropractic adjustment (5\%) and massage (2\%).

There were no published surveys found that explored how it would be determined if or when a horse needed time off from regular work for a non-physical issue. In this survey, THR programs depended on horse handlers or barn managers to recognize the symptoms of burn-out. From the choices offered, the most common reason horses were given time off was due to an unexplained change in behavior. Some programs reported increasing incidents of spooking or shying as reasons for giving a horse time off.

\section{Conclusions}

It is acknowledged that there were some ambiguous and confusing responses collected for this pilot survey. Future surveys should consider revising the questions to generate more precise data (Table 4).

Table 4. Question revisions recommended by authors for future surveys

\begin{tabular}{|c|c|}
\hline \multirow{3}{*}{$\begin{array}{l}\text { Question } \\
1\end{array}$} & Recommended Change(s) \\
\hline & $\begin{array}{l}\text { Edit to read, "Do you offer riding in sessions (defined as a group of rides over a period of } \\
\text { weeks)?" }\end{array}$ \\
\hline & Add, "If yes, how long is a session?" \\
\hline New & $\begin{array}{l}\text { Create question, "How long is the average lesion length (defined as the length of time } \\
\text { spent during one ride?" }\end{array}$ \\
\hline 4 & Specify to enter minutes \\
\hline 8 & $\begin{array}{l}\text { Edit to read, "What is the most common reason horses leave your program after any trial } \\
\text { period?" }\end{array}$ \\
\hline 9 & $\begin{array}{l}\text { In ability descriptions, replace 'pulling on horse's mouth' with 'pulling on horse's mouth or } \\
\text { head with reins' }\end{array}$ \\
\hline 10 & Add a choice with Attention Disorders (ADHD, ADD) \\
\hline 13 & $\begin{array}{l}\text { Edit to read, "How do you determine if horses need time off from the program for reasons } \\
\text { other than a physical issue?" }\end{array}$ \\
\hline & Add 'Once per year by Veterinarian' and 'Twice per year by Veterinarian' as choices \\
\hline
\end{tabular}


Remove 'Once per session by Veterinarian' as a choice

Change question type to choose one and not enter percentage

19

Provide breed examples with each breed category option

253

254

255

256

257

258

259

260

261

262

263

264

265

266

267

268

269

270

271

272

273

274

275

276

277

278

279

280

281

282

283

284

Based on data gathered in this survey, it can be concluded that THR horses were not worked excessively. They were ridden less than PATH Intl.'s maximum recommendation of 6 hours/day (ridden 2 hours/day in this survey) and 6 days/week (used 4 days/week in this survey) [10]. They were ridden similarly to those in university programs, where horses were ridden 7 hours/week and used 4 days/week (approximately 1.8 hours/day that they were ridden) [11]. Horses in THR programs also appeared to have fewer reported health issues in most categories as compared with data in other national reports. This reflects positively on horse use and care in these programs.

\section{Acknowledgements}

The authors would like to thank all PATH Intl.-affiliated therapeutic horseback riding programs that responded to the survey.

\section{References}

[1] Bass MM, Duchowny CA, Llabre MM. The effect of therapeutic horseback riding on social functioning in children with autism. J Autism Dev Disord 2009;39:1261-7.

[2] Rigby BR, Grandjean PW. The efficacy of equine-assisted activities and therapies on improving physical function. J Altern Complement Med 2016;22:9-24.

[3] Sterba JA, Rogers BT, France AP, Vokes DA. Horseback riding in children with cerebral palsy: effect on gross motor function. Dev Med Child Neurol 2002;44:301-8.

[4] Davis E, Davis B, Wolfe R, Raadsveld R, Heine B, Thomason P, et al. A randomized controlled trial of the impact of therapeutic horse riding on the quality of life, health, and function of children with cerebral palsy. Dev Med Child Neurol 2009;51:111-9.

[5] Gabriels RL, Agnew JA, Holt KD, Shoffner A, Zhaoxing P, Ruzzano S, et al. Pilot study measuring the effects of therapeutic horseback riding on school-age children and adolescents with autism spectrum disorders. Res Autism Spectr Disord 2012;6:578-88.

[6] Cherng R, Liao h, Leung HW, Hwang A. The effectiveness of therapeutic horseback riding in children with spastic cerebral palsy. Adapt Phys Activ Q 2004;21:103-21.

[7] Malinowski K, Yee C, Tevlin JM, Birks EK, Durando MM, Pournajafi-Nazarloo H, et al. The effects of equine assisted therapy on plasma cortisol and oxytocin concentrations and heart rate variability in horses and measures of symptoms of post-traumatic stress disorder in veterans. J Equine Vet Sci 2018;64:17-26. 
[8] PATH Intl. About the Professional Association of Therapeutic Horsemanship International. 2018. https://www.pathintl.org/about-path-intl/about-path-intl. Accessed Jan 23, 2018.

[9] Ross WA, Kaneene JB. An operation-level prospective study of risk factors associated with the incidence density of lameness in Michigan (USA) equine operations. Prev Vet Med 1996;28:209-24.

[10] PATH Intl. Equine Welfare and Management Standards. 2018 ed. https://www.pathintl.org/images/pdf/standards-manual/2018/2018-path-intl-standards-completemanual.pdf. Accessed March 20, 2018.

292 [11] Zhao H. Horse use and management in university equine programs. (Master's Thesis).

293 https://digitalcommons.murraystate.edu/cgi/viewcontent.cgi?article=1080\&context=etd

294 [12] Dillman DA, Smyth JD, Christian LM. Internet, phone, mail, and mixed-mode surveys: the tailored design method. $4^{\text {th }}$ ed. Hoboken: John Wiley \& Sons; 2014.

[13] APHIS Veterinary Services. Report 1 Baseline reference of equine health and management in the United States, 2015. 2016. https://www.aphis.usda.gov/animal health/nahms/equine/downloads/equine15/Eq2015 Rept1.pdf. Accessed January 17, 2020.

[14] Delaware Department of Agriculture. Delaware Equine Industry Survey. 2004.

301 https://www.nass.usda.gov/Statistics by State/Delaware/Publications/Misc/2EquineSurveyFULL.pdf. Accessed January 17, 2020.

[15] Kentucky Horse Council. 2012 Kentucky Equine Survey. 2013. https://uknowledge.uky.edu/cgi/viewcontent.cgi?article=1000\&context=equine reports. Accessed January 17, 2020.

[16] Dashper K, Fenner K, Hyde M, Probyn-Rapsey F, Caspar G, Henshall C, et al. The anthropomorphic application of gender stereotypes to horses. Anthrozoos 2018;31:673-684.

[17] APHIS Veterinary Services. Age-related trends in demographics of equids in the United States. 2018. https://www.aphis.usda.gov/animal health/nahms/equine/downloads/equine15/Equine15 is TrendsA 310 ge.pdf. Accessed January 17, 2020.

311 [18] Lawrence LM, Cymbaluk NF, Freeman DW, Goer RJ, Graham-Thiers PM, Lonland AC, et al. Nutrient 312 Requirements of Horses. 6th ed. Washington, D.C.: The National Academies Press; 2007.

313 [19] Hovey M, Santiago ML, Porr CA. Sustaining experiential education in a university agriculture 314 program using alternative funding sources and strategic planning. NACTA J 2018;62:243-248.

315 [20] APHIS Veterinary Services. Report 3 equine management and select equine health conditions in the $316 \quad$ United States, 2015. 2017.

317 https://www.aphis.usda.gov/animal health/nahms/equine/downloads/equine15/Eq2015 Rept3.pdf.

318 Accessed January 17, 2020.

319 [21] APHIS Veterinary Services. Report 2 Changes in the U.S. equine industry, 1998-2015. 2017.

320 https://www.aphis.usda.gov/animal health/nahms/equine/downloads/equine15/Eq2015 Rept2 1.pdf.

321 Accesses January 17, 2020. 